\title{
Progesterone-induced RNA Hand2os1 regulates decidualization in mice uteri
}

\author{
Yanni Jia' ${ }^{1,2, *}$, Rui Cai ${ }^{1,2, *}$, Tong Yu ${ }^{1,2}$, Ruixue Zhang ${ }^{1,2}$, Shouqin Liu ${ }^{1,2}$, XinYan Guo ${ }^{1,2}$, \\ Chunmei Shang ${ }^{1,2}$, Aihua Wang ${ }^{1,2}$, Yaping Jin ${ }^{1,2}$ and Pengfei Lin ${ }^{1,2}$ \\ ${ }^{1}$ College of Veterinary Medicine, Northwest A\&F University, Yangling, Shaanxi, China and ${ }^{2}$ Key Laboratory of Animal \\ Biotechnology, Ministry of Agriculture and Rural Affairs, Northwest A\&F University, Yangling, Shaanxi, China \\ Correspondence should be addressed to P Lin or Y Jin; Email: linpengfei@nwsuaf.edu.cn or yapingjin@163.com
}

*(Y Jia and R Cai contributed equally to this work)

\begin{abstract}
Decidualization is a critical process for successful embryo implantation and subsequent placenta formation. The characterization and physiological function of IncRNA during decidualization remain largely unknown. In the present study, we conducted RNA-

sequencing analysis to compare gene expression between decidua of days 6 and 8, and normal pregnant endometrium (day 4). A total of 2332 high-confidence putative IncRNA transcripts were expressed. Functional clustering analysis of cis and trans IncRNA targets showed that differentially expressed IncRNAs may regulate multiple gene ontology terms and pathways that have important functions in decidualization. Subsequent analyses using qRT-PCR validated that eight of all IncRNAs were differentially regulated in mice uteri during decidualization, both in vivo and in vitro. Furthermore, we showed that differentially expressed IncRNA of Hand2os1 was specifically detected in stromal cells on days 2 to 5 of pregnancy and was strongly upregulated in decidual cells on days 6-8 of pregnancy. Similarly, Hand2os1 expression was also strongly expressed in decidualized cells following artificial decidualization, both in vivo and in vitro. In uterine stromal cells, $\mathrm{P}_{4}$ was able to significantly upregulate the expression of Hand2os1, but upregulation was impeded by RU486, whereas $E_{2}$ appeared to have no regulating effect on Hand2os1 expression. Concurrently, Hand2os1 significantly promoted the decidual process in vitro and dramatically increased decidualization markers Prl8a2 and Prl3c1. Our results provide a valuable catalog for better understanding of the functional roles of IncRNAs in pregnant mouse uteri, as it relates to decidualization. Reproduction (2020) 159 303-314
\end{abstract}

\section{Introduction}

In early pregnancy, the extensive remodeling of maternal endometrium is critical for successful implantation of the blastocyst and subsequent placenta formation, which is characterized by rapid proliferation and differentiation of endometrial stromal cells (ESCs) into decidual cells. This process is known as decidualization. The morphological and functional transformation of this process in decidual stromal cells contributes to uterine hemostasis, angiogenesis, and immune response during implantation and pregnancy (Schatz et al. 2016). Defective decidualization at the site of implantation is associated with several pregnancy complications, such as early pregnancy defects/loss, preeclampsia, uteroplacental disorders, endometriosis, intrauterine growth restriction, and recurrent pregnancy loss (Mori et al. 2016, Garrido-Gomez et al. 2017). On day 4 of mouse pregnancy (day $1=$ vaginal plug), ovarian $\mathrm{P}_{4}$ and preimplantation $E_{2}$ secretion renders the uterus receptive to the blastocyst, which is the prerequisite for embryo implantation and decidualization. The proliferating stromal cells at the antimesometrial pole surrounding the implanting blastocyst undergo differentiation into decidual cells and form the primary decidual zone (PDZ) on roughly the afternoon of day 5. During days 6-7 of pregnancy, stromal cells adjacent to the PDZ continue to proliferate and differentiate into polyploidy decidual cells, forming the secondary decidual zone (SDZ). At this point, the cells comprising the PDZ have degenerated progressively by apoptosis (occurring on day 7 of pregnancy) and have for the most part disappeared at day 8 . After day 8 , placental and embryonic growth slowly replaces the SDZ (Das 2009, 2010). Numerous signaling molecules and factors, including homeobox transcription factors, cell-cycle molecules, cytokines, growth factors, signaling mediators, extracellular matrix remodeling factors, steroid hormones, and endometrial autocrine and paracrine factors, have been implicated in the progression of decidualization. Nevertheless, the precise cellular and molecular mechanism underlying decidualization remains unclear.

Transcriptome analysis revealed that more than $90 \%$ of DNA sequences actively transcribed proteins but that 
only $2 \%$ of it is responsible for encoding proteins. Thus, the majority of transcripts are referred to as ncRNAs, which can be categorized into infrastructural ncRNAs and regulatory ncRNAs (Birney et al. 2007). On the basis of their size, regulatory ncRNAs can be classified into small ncRNAs and IncRNAs (Ponting et al. 2009). Small ncRNAs, such as miRNA, have been found to play essential roles in endometrial receptivity, decidualization, and embryo implantation (Liang et al. 2017, Paul et al. 2019). LncRNAs are transcripts longer than 200 nucleotides that are frequently capped, polyadenylated, and spliced, with highly tissue-specific/cell-specific expression patterns and less conservation across multiple species. Recent studies revealed that IncRNAs are associated with oogenesis, ovary development, oocyte maturation, and embryo development, trophoblast cell migration, as well as placentation, suggesting that IncRNAs may play an important functional role in female mammalian reproductive processes (Hamazaki et al. 2015, Taylor et al. 2015, Bouckenheimer et al. 2016, Liu et al. 2018). In contrast, the expression and biological function of IncRNAs during embryo implantation remain largely unknown.

In this paper, we report systematic identification of IncRNAs in the endometrial tissue of pregnant mice on day 4 (D4U), day 6 (D6U), and day 8 (D8U) at implantation sites, using RNA sequencing (RNA-seq). Gene ontology (GO) enrichment and Kyoto Encyclopedia of Genes and Genomes (KEGG) pathway analysis were carried out to predict the possible functions of cis and trans IncRNA targets. Eight differentially expressed IncRNAs were validated by quantitative RT-PCR (qRT-PCR) during in vivo and in vitro decidualization. One IncRNA Hand2os 1 (Uph, also known as HAND2-AS1 in humans) was selected for further investigation of the biological functions involved in the decidualization process, using over-expressing and silencing. Our results suggest that $\mathrm{P}_{4}$ induced Hand2os 1 expression in ESCs in a progesterone receptor (PR)-dependent manner; this process may in turn be involved in the decidual process, via regulation of the following decidualization markers: prolactin family 8 , subfamily a, member 2 (Pr/8a2) and prolactin family 3 , subfamily $\mathrm{c}$, and member 1 (Pr/3c1) expression. The present study serves as a valuable resource for the systematic annotation and expression profiling of IncRNAs and provides a foundation for future studies aimed at understanding their role in decidualization.

\section{Materials and methods}

\section{Ethics statement}

The methods used in this study were performed in accordance with the guidelines of the Committee for the Ethics on Animal Care and Experiments at Northwest A\&F University. All experimental protocols involving animal subjects were approved by the Committee for the Ethics on Animal Care and Experiments at Northwest A\&F University.

\section{Animals, treatments, and sample collection}

Mature mice (Kunming white strain) aged 8-10 weeks were purchased from the Laboratory Animal Center of The Fourth Military Medical University (Shaanxi, China). The mice were caged in a temperature and light-controlled room $(12 \mathrm{~h}$ light:12 h darkness cycle). Food and water were provided ad libitum.

Female mice were mated with fertile male mice from the same breed to induce pregnancy. Pregnancy on days 1 and 4 (day $1=$ day of vaginal plug) was confirmed by recovering embryos from the oviduct and uterus, respectively. On the above pregnant days, mice were killed at 09:00 h by cervical dislocation, and the entire endometrium and myometrium were removed by extrusion method and immediately collected. Decidual tissue was collected from the implantation site on days 6 to 8 of pregnancy; the procedure was performed according to that described by Shea and Geijsen (2007). All samples were immediately transferred into an RNAstore Reagent (Tiangen, Beijing, China) and stored at $-20^{\circ} \mathrm{C}$. The endometrium of five mice during each pregnant day was pooled together for further RNA analysis and library construction. Three biological replicates per sample, combined from five mice, were performed.

Mouse models involving pseudopregnancy, artificial decidualization, and hormonal treatment were produced as described in our previous reports (Lan et al. 2013, Lin et al. 2014, Xiong et al. 2016). Pseudopregnant female mice were obtained by mating to vasectomized males of proven sterility, and the entire uterus of pseudopregnant mice was collected between days 1 and 6 . One of the uterine horns were infused with $25 \mu \mathrm{L}$ sesame oil on day 4 of pseudopregnancy to induce artificial decidualization, and the contralateral, untreated horn served as a control. In the hormone treatment model, the ovariectomized mice were subcutaneously injected after 2 weeks with either $E_{2}$ (100 ng/mouse), $P_{4}$ (1 mg/mouse), a combination of both, or $\mathrm{P}_{4}(1 \mathrm{mg} /$ mouse) plus RU486 (10 mg/mouse) (Sigma). Following on, uterine tissue was collected $24 \mathrm{~h}$ following the previously mentioned treatment. Meanwhile, the control animals received the sesame amount of sesame oil ( $0.1 \mathrm{~mL} /$ mouse).

\section{Isolation of mouse ESCs and induction of decidualization in vitro}

Uterine horns of day 4 pregnant mice were dissected longitudinally, washed with Hanks' balanced salt solution (HBSS), and cut into 3-5 mm pieces. Each uterine horn was placed in HBSS containing 0.25\% trypsin (Sigma) for $1 \mathrm{~h}$ at $4^{\circ} \mathrm{C}$, followed by $1 \mathrm{~h}$ at room temperature, and then $10 \mathrm{~min}$ at $37^{\circ} \mathrm{C}$. After discarding the supernatant and washing twice with $\mathrm{HBSS}$, the remaining tissue was then incubated in HBSS containing $0.05 \%$ collagenase (Sigma) at $37^{\circ} \mathrm{C}$ for $45 \mathrm{~min}$. The digested tissue was vortexed for $20 \mathrm{~s}$ and filtered through a $70 \mu \mathrm{m}$ filter (Cell Strainer, Millipore). The isolated cells were re-suspended and washed with a DMEM/F12 culture medium and then seeded in a DMEM/F12 culture medium with 
$100 \mathrm{U} / \mathrm{mL}$ penicillin, $100 \mu \mathrm{g} / \mathrm{mL}$ streptomycin, and $10 \%$ charcoal-treated fetal bovine serum (cFBS, Life Technologies) at a concentration of $5 \times 10^{5}$ cells/well in $60 \mathrm{~mm}$ dishes. Following incubation for $2 \mathrm{~h}$, unattached cells were removed by wash with HBSS. The attached cells were plated in DMEM/ F12 with $10 \%$ cFBS and allowed to further attach for $6 \mathrm{~h}$. Then, stromal cells were treated with $10 \mathrm{nM}$ estradiol-17 $\beta$ (Sigma) and $1 \mu \mathrm{MP}_{4}$ (Sigma) to induce decidualization, and cells were harvested 0, 24, 48, and 72 h later. Mouse Prl8a2 was detected using QRT-PCR as a reliable decidualization marker.

\section{RNA-seq analysis}

LncRNA expression profiles of mouse decidualized endometrium were generated using an Illumina Hiseq ${ }^{\mathrm{TM}}$ 2500 platform and analyzed by Novogene Bioinformatics Technology Co., Ltd. (Beijing, China). The library construction, quality control, transcriptome assembly, and screening of candidate IncRNAs were obtained as Supplementary methods (see section on supplementary materials given at the end of this article). Paired-end clean reads of high quality were mapped to the mouse GRCm38.p6 reference genome (ftp:// ftp.ncbi.nlm.nih.gov/genomes/Mus_musculus/Assembled_ chromosomes/seq/). Sub-types of the annotated IncRNAs were included in the latest gene/transcript biotypes in the Ensembl database. We searched coding genes 100k upstream and downstream of all identified IncRNAs to represent putative cis target genes. For trans fashion, we calculated the expressed correlation between IncRNAs and coding genes, using custom scripts to search common expression modules, and subsequently analyzed their function. The differentially expressed IncRNAs between any two samples were identified using a $P$-adjust $<0.05$, according to fragments per kilobase of exon per million fragments mapped (FPKM). The GO initiative and the KEGG database were used to conduct functional enrichment analysis of the targeted genes of differentially expressed IncRNAs. The lower the $P$ value, the more prominent the relevance; only GO terms or KEGG pathways with corrected $P$-values $<0.05$ were considered as being significantly enriched.

\section{qRT-PCR analysis}

Total RNA was extracted using TRIzol Reagent (Invitrogen). RT was performed using the $5 \mathrm{X}$ All-In-One RT MasterMix with AccuRT Genomic DNA Remove Kit (Applied Biological Materials Inc. BC, Canada), as per the manufacturer's instructions. qRT-PCR was performed using the EvaGreen qPCR Mastermix Kit (Applied Biological Materials Inc. BC, Canada) on the CFX96 ${ }^{\mathrm{TM}}$ Real-Time PCR Detection System (Bio-Rad Laboratories, Inc.). All reactions were conducted in biological triplicate. The relevant primers and temperatures employed are listed in Supplementary Table 1. The authenticity of the PCR products was verified by melting curve analysis and $2 \%$ agarose gel electrophoresis. Gene expression levels were calculated using the $2^{-\Delta \Delta C t}$ analysis method. Final data were expressed as the mean \pm S.E.M. and analyzed using a one-way ANOVA, followed by Fisher's least significant difference test and independent samples $t$-test, using SPSS software (v.23.0;
SPSS, Inc.). Differences were considered significant when $P$ was $<0.05$.

\section{Detecting target RNA via RNAscope}

Uterine tissue were formalin-fixed, paraffin-embedded, and sliced into $5 \mu \mathrm{m}$ thick sections for detecting target RNA via RNAscope (Advanced Cell Diagnostics, Newark, CA, USA). Detection of Hand2os 1 expression via probe targeting was performed on uterine tissue using an RNAscope 2.5 High Definition-BROWN Assay Kit, as per the manufacturer's instructions (Advanced Cell Diagnostics, USA). Finally, the previously noted tissue sections were counterstained with hematoxylin. Images were acquired using a fluorescence microscope (Nikon).

\section{Transfection of IncRNA siRNA and overexpression vector}

Mouse ESCs were transfected with a Hand2os1 siRNA or negative control, designed, and synthesized by Gene Pharma Co., Ltd. (Shanghai, China), using a TurboFect Transfection Reagent (Thermo Scientific), as per the manufacturer's instructions. Following incubation with the IncRNA siRNA for $24 \mathrm{~h}$, the medium was replaced with DMEM/F12 containing $10 \% \mathrm{cFBS}, 10 \mathrm{nM} \mathrm{E}_{2}$, and $1 \mu \mathrm{M} \mathrm{P}_{4}$, to induce decidualization. The previously noted cells were harvested at the indicated time points for decidual marker gene analysis. The target sequences of siRNAs were as follows: 5'-GGGAACUGACUGCAGUCCUTT and 5'-AGGACUGCAGUCAGUUCCCTT (Hand2os 1 SIRNA); 5'-UUCUCCGAACGUGUCACGUTT and 5'-ACGUGACACGUUCGGAGAATT (non-specific scrambled siRNA, negative control).

Full-length Hand2os1 cDNA fragments from mice uteri were amplified by PCR using the following primers: 5'-GAATTC (ECORI) CACTCATAACCATAAGATAATTAAAACGG and $\quad 5^{\prime}$-TCTAGA $(X b a l) \quad$ TTTAAAAAA TAATTTTTAATATACTATGTGCATGGTTGG. The Hand2os 1 and pcDNA3.1 vector were cut by EcoRI/Xbal (Takara) at $37^{\circ} \mathrm{C}$ for $12 \mathrm{~h}$; the target segments were then ligated into pcDNA3.1 using Solutionl (Takara Biotechnology) at $16^{\circ} \mathrm{C}$ for $4 \mathrm{~h}$, in order to construct pcDNA3.1-Hand2os1. The vector was transfected into mouse ESCs using a TurboFect Transfection Reagent (Thermo Scientific), as per the manufacturer's instructions. An empty pcDNA3.1 vector was used as a control.

\section{Results \\ Decidual tissue collection and validation}

To identify the integrity of isolated endometrium and confirm that the embryo and myometrium had been removed intactly, the mRNA expression of decidualization marker genes, alkaline phosphatase Alpl and Prl8a2, were examined, respectively. Consistent with previous reports, Prl8a2 mRNA was significantly up-regulated, which accompanied decidualization (Supplementary Fig. 1A). Additionally, Alpl, another 
typical decidualization marker, was detected at high levels on day 6 of pregnancy but decreased on day 8 (Supplementary Fig. 1B). This pattern was similar to those previously reported in mice (Pollard et al. 1990, Herington et al. 2009). Meanwhile, caudal type homeobox $2(C d \times 2)$, the transcription factor expressed specifically in the developing trophectoderm (Wu et al. 2010) was not detected in our isolated endometrium on pregnancy days 4,6 , or 8 , respectively. Furthermore, the significantly reduced mRNA levels of a smooth musclemaker gene, alpha smooth muscle actin (Acta2) (Gao et al. 2015), was observed in the isolated endometrium, compared with the entire group of uterine samples for the same pregnant days, respectively $(P<0.01$, Supplementary Fig. 1C). Acta2 was consistently measured on blood vessels throughout the endometrial stroma during early pregnancy (Kaitu'u-Lino et al. 2012).

\section{Genome-wide identification and characterization of IncRNAs in mouse endometrium during decidualization}

In order to systematically detect the expression of IncRNAs during decidualization, cDNA libraries were constructed from mouse endometrium on pregnant $\mathrm{D} 4 \mathrm{U}$, $\mathrm{D} 6 \mathrm{U}$, and $\mathrm{D} 8 \mathrm{U}$, respectively. An average of between $104,000,000$ and 122,000,000 raw reads were generated, and approximately $97.02-97.12 \%$ of clean reads among raw reads in each sample were obtained following stringent filtering (Supplementary Table 2). Subsequently, we mapped the clean reads to the reference genome of Mus musculus using TopHat v2.0.9. The percentage of mapped clean reads in each sample ranged from 89.90 to $91.54 \%$, of which 64.04 to $73.20 \%$ were mapped uniquely to only one location. The mapped reads from each sample were assembled and merged using Cufflinks (v2.1.1) and Cuffmerge, respectively, and a total of 127,671 unique assembled transcripts were produced.

In order to obtain a comprehensive IncRNA transcript set, highly stringent filtering conditions were implemented, as shown in Supplementary Fig. 2, according to the structural and functional characteristics of IncRNAs. Finally, a total of 2332 putative IncRNA transcripts were identified, including 1822 annotated IncRNA transcripts (1439 genes) and 510 novel IncRNA transcripts (388 genes) (Supplementary Table 3). Overall, the genomic features of novel IncRNAs were similar to the annotated IncRNAs in our study. Consistent with existing reports, differences in genomic features were observed between IncRNAs and protein-coding genes (Supplementary Fig. 3).

\section{Identification of differentially expressed IncRNAs in decidualized cells}

Upon further analysis, according to FPKM values, 334 differentially expressed IncRNA transcripts were identified in mouse endometrium during decidualization (Supplementary Table 4). There were 182 differentially expressed IncRNA transcripts in D6U vs D4U groups, of which 77 transcripts were significantly upregulated and 105 transcripts were significantly downregulated. Furthermore, a total of 226 IncRNA transcripts were differentially expressed, on the basis of pairwise comparisons between the $\mathrm{D} 8 \mathrm{U}$ and $\mathrm{D} 4 \mathrm{U}$ groups, with 99 transcripts upregulated and 127 transcripts downregulated. We identified 87 IncRNA transcripts with significant expression differences between the $\mathrm{D} 8 \mathrm{U}$ and $\mathrm{D} 6 \mathrm{U}$ groups among these 44 upregulated and 43 downregulated transcripts. Overall, the number of downregulated IncRNAs was higher than the number of upregulated IncRNAs during decidualization. As shown in Table 1 and Supplementary Table 4, 16 differentially expressed IncRNA transcripts were commonly identified in all three groups. Meanwhile, two IncRNA transcripts (ENSMUST00000184645.1 and ENSMUST00000126270.1) were differentially upregulated and five IncRNA transcripts (ENSMUST00000172910.1, ENSMUST00000181955.1, ENSMUST00000186411.1, ENSMUST00000185789.1, and LNC_000225) were differentially downregulated, in a stage-dependent manner.

\section{GO and KEGG pathway analysis of differentially expressed IncRNA target genes}

To investigate the potential functions of IncRNAs, we first predicted the differentially expressed IncRNA cis- and trans-acting target genes (Supplementary Tables 5 and 6). The significantly enriched cis GO terms of IncRNA targets in the D6U vs D4U groups were similar to D8U vs D4U groups and associated primarily with cell proliferation, differentiation, migration, and angiogenesis, which contributed to endometrium re-building and decidualization (Supplementary Fig. 4). In addition, the top 30 significantly enriched trans GO terms were similar in the three comparison groups, indicating that the regulating function of these IncRNAs may be preserved in the process of decidualization. The majority of enriched $\mathrm{GO}$ terms of the differential expression IncRNA target genes in the present study were similar to previous work conducted involving uterine mRNA expression profiles during decidualization (McConaha et al. 2011, Sroga et al. 2012, Liu \& Wang 2015).

Compared with those in the D4U group, the most enriched KEGG pathways of cis and trans target IncRNAs in the D6U and D8U groups primarily included a metabolic pathway, estrogen signaling pathway, cancer pathway, the PI3K-Akt signaling pathway, HTLV-I infection, the MAPK signaling pathway, and the Ras and Ras1 signaling pathways. Meanwhile, the most enriched pathways in the D8U vs D6U groups for cis included an oxytocin signaling pathway, a cAMP signaling pathway, and a calcium signaling pathway (Supplementary Tables 7 and 8). 
Table 1 Sixteen differentially expressed IncRNA transcripts were commonly identified in all the three groups.

\begin{tabular}{|c|c|c|c|c|c|}
\hline Transcript ID & Gene ID & Gene name & D4U FPKM & D6U FPKM & D8U FPKM \\
\hline ENSMUST00000136359.3 & ENSMUSG00000000031.11 & $\mathrm{H} 19$ & 40.5661 & 131.543 & 65.4112 \\
\hline LNC_000368 & XLOC_032091 & & 0.242036 & 3.30358 & 1.47354 \\
\hline ENSMUST00000172910.1 & ENSMUSG00000091562.3 & Gm9581 & 18.467 & 10.0689 & 5.6804 \\
\hline ENSMUST00000184645.1 & ENSMUSG00000062036.8 & Gm19518 & 0 & 1.36506 & 6.52689 \\
\hline ENSMUST00000151426.1 & ENSMUSG00000085114.1 & 1600025M17Rik & 0 & 13.0193 & 0.584374 \\
\hline LNC_000021 & XLOC_003243 & & 2.53321 & 0.0612518 & 0.464945 \\
\hline ENSMUST00000181955.1 & ENSMUSG00000074415.6 & 2610203C20Rik & 6.46048 & 1.5733 & 0.321162 \\
\hline ENSMUST00000181075.1 & ENSMUSG00000096980.1 & Gm26526 & 1.07335 & 3.43487 & 0.116526 \\
\hline ENSMUST00000156068.2 & ENSMUSG00000018451.6 & 6330403K07Rik & 11.1774 & 0.749637 & 19.8742 \\
\hline ENSMUST00000126270.1 & ENSMUSG00000085931.1 & Gm12648 & 0 & 2.19169 & 5.76829 \\
\hline LNC_000225 & XLOC_019711 & & 15.6081 & 2.52168 & 0 \\
\hline ENSMUST00000186386.2 & ENSMUSG00000100510.2 & Hand2os1 & 36.048 & 276.613 & 97.4685 \\
\hline ENSMUST00000186411.1 & ENSMUSG00000100303.1 & 2600014E21Rik & 1.33655 & 0.55117 & 0.20727 \\
\hline ENSMUST00000192860.1 & ENSMUSG00000104022.1 & CAAA01187608.2 & 0.890325 & 16.9395 & 3.18089 \\
\hline ENSMUST00000185789.1 & ENSMUSG00000101609.1 & Kcnq1 ot1 & 6.38982 & 4.04542 & 2.66331 \\
\hline ENSMUST00000128111.1 & ENSMUSG00000087067.1 & Gm11532 & 0.096742 & 2.1489 & 0.821279 \\
\hline
\end{tabular}

\section{Experimental validation of differentially expressed IncRNAs}

To validate RNA-seq data, we selected eight differentially expressed IncRNAs and examined their expression patterns during the decidualization process by qRT-PCR
(Fig. 1). In general, the qRT-PCR results confirmed that the expression patterns of these IncRNAs were consistent with their expression trend, calculated from the RNA-seq data. Compared with those at day 1 of pregnancy, the RIKEN cDNA C630043F03 gene (C630043F03Rik) and predicted gene 14133 (Gm14133) were significantly
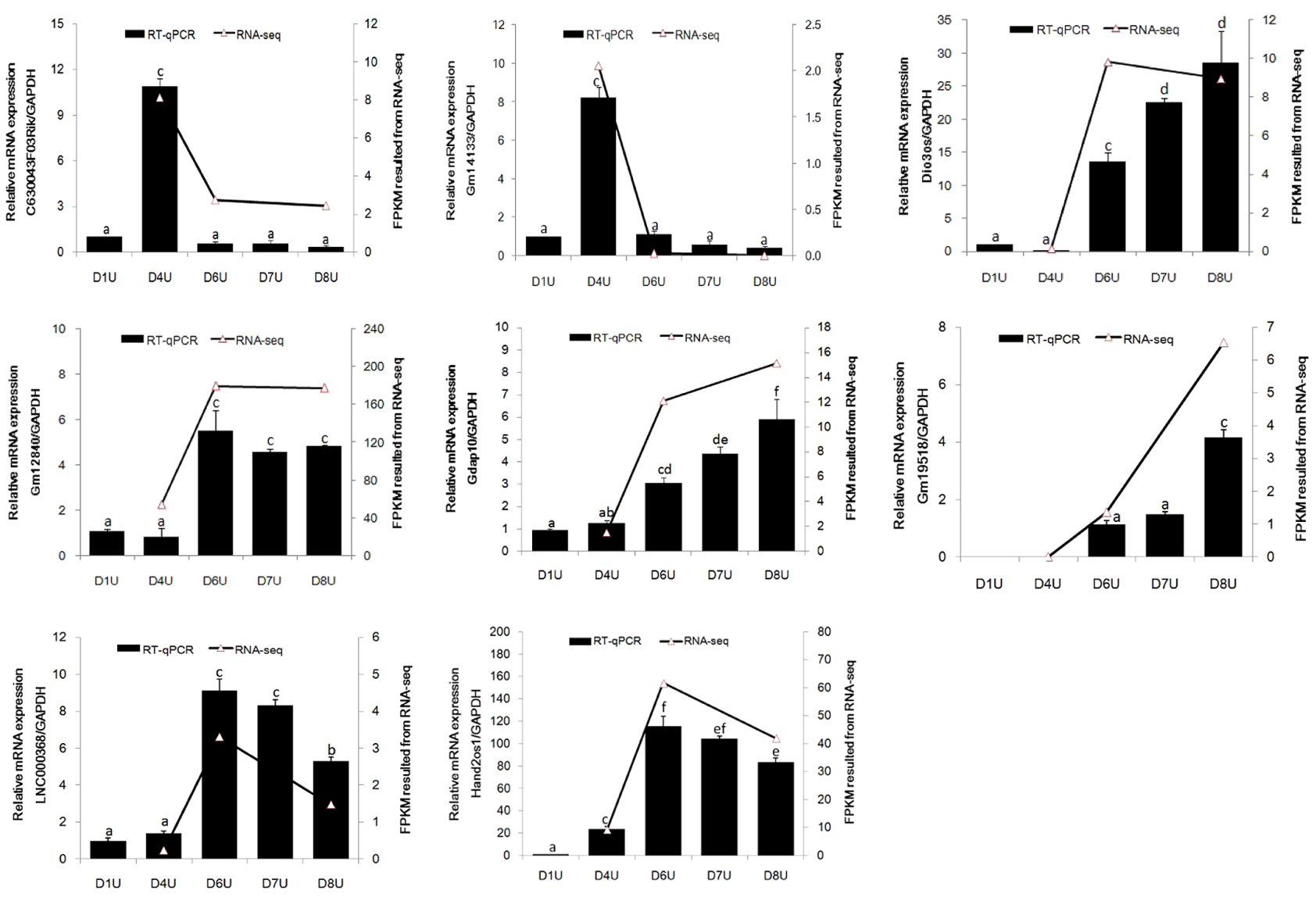

Figure 1 Validation of eight differentially expressed IncRNAs by qRT-PCR in pregnant mice uteri. Glyceraldehyde 3-phosphate dehydrogenase $(\mathrm{GAPDH})$ was used as a reference gene for normalization. The data are expressed as the mean \pm S.E.M. of three replicates, and the bar bearing different superscripts indicates a significant difference between the mean values $(P<0.05)$. 

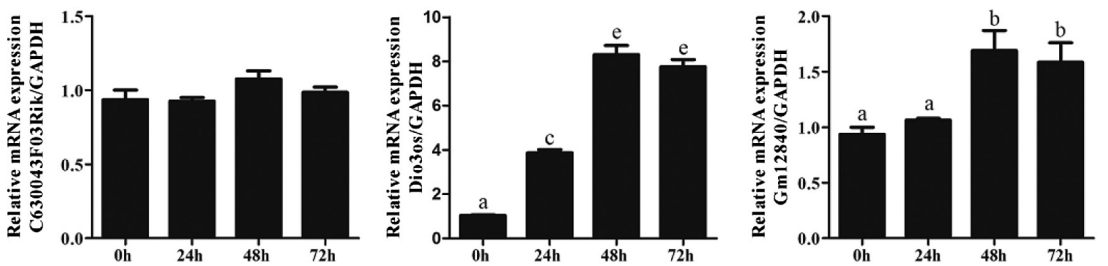

Figure 2 The qRT-PCR analyses of expression levels for differentially expressed IncRNAs during decidualization in vitro. The mouse ESCs collected on day 4 of pregnancy were decidualization induced with $\mathrm{P}_{4}(1 \mu \mathrm{M})$ and $\mathrm{E}_{2}$ $(10 \mathrm{nM})$. Then, the ESCs were harvested at
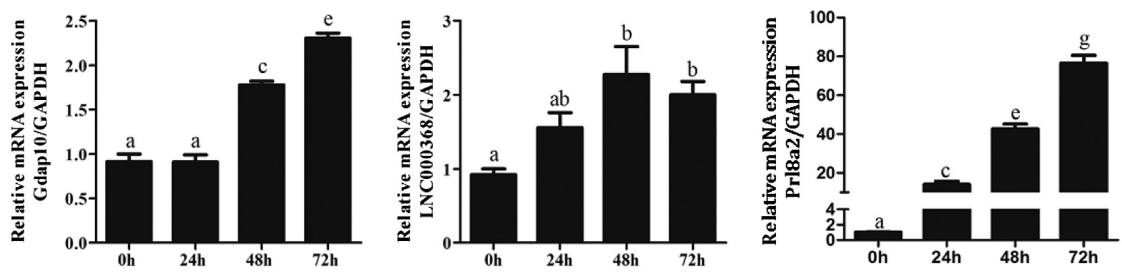
various times for qRT-PCR analysis. GAPDH was used as a reference gene for normalization. Pr/8a2 was detected using qRT-PCR as a reliable decidualization marker. The data are expressed as the mean \pm S.E.M. of three replicates, and the bar bearing different superscripts indicates a significant difference between the mean values $(P<0.05)$.

upregulated at day 4 of pregnancy, and no significant difference was observed on days 6-8 of pregnancy $(P<0.05)$. Deiodinase, iodothyronine type III, opposite strand upstream RNA (Dio3os), predicted gene 12840 (Gm12840), and ganglioside-induced differentiationassociated protein 10 (Gdap10) expression levels from days $6-8$ of pregnancy were significantly higher than those for days 1 and 4 , respectively $(P<0.05)$. Interestingly, MAP/microtubule affinity-regulating kinase 1 and pseudogene 3 (Gm19518) was not observed for days 1 and 4 pregnant mouse uteri, and the expression level of Gm19518 was significantly upregulated during decidualization. The highest expression level was detected on day 8 of pregnancy $(P<0.05)$. Compared with those on days 1 and 4 of pregnancy, LNC000368 and Hand2os 1 expression levels increased dramatically on day 6 and were then significantly down-regulated on day 8 of pregnancy $(P<0.05)$.

To evaluate the physiological function of the previously validated IncRNAs, which obtained significant up- or downregulation during decidualization in vivo, we further detected its expression changes during decidualization in vitro and under artificial decidualization, respectively (Figs 2 and 3). In agreement with the results of RNA-seq data, no significant difference was detected in C630043F03Rik level during decidualization in vitro. Dio3os, Gm12840, Gdap10, and LNC000368 levels significantly increased in a time-dependent manner during ESC decidualization in vitro $(P<0.05)$. Furthermore, Gm14133 and Gm19518 were not detected in either cultured ESCs or decidual ESCs in vitro. Consistent with the results, the expression levels of Dio3os, Gm12840, Gdap10, LNC000368, and Hand2os 1 were also significantly higher in the group undergoing artificial decidualization, compared with those in the control group $(P<0.05)$. Taken together, these results further support the reliability of RNA-seq data and indicate that these differentially expressed IncRNAs may play a role in ESC decidualization.

\section{Expression pattern of Hand2os1 in mice uteri during early pregnancy}

To better evaluate the physiological function of differentially expressed IncRNA Hand2os 1 in RNAseq data, RNAscope was performed to analyze the spatiotemporal distribution of Hand2os 1 in the uteri of pre-implantation pregnant mice (Fig. 4). Although Hand2os 1 could be detected using qRT-PCR in day 1 pregnant uteri, positive staining was too low to be detected by RNAscope (Figs 1 and 4). A weak Hand2os 1 signal was detected in a sub-population of ESCs near the luminal epithelium on day 2 of pregnancy. Hand2os 1 gradually increased and was primarily localized in
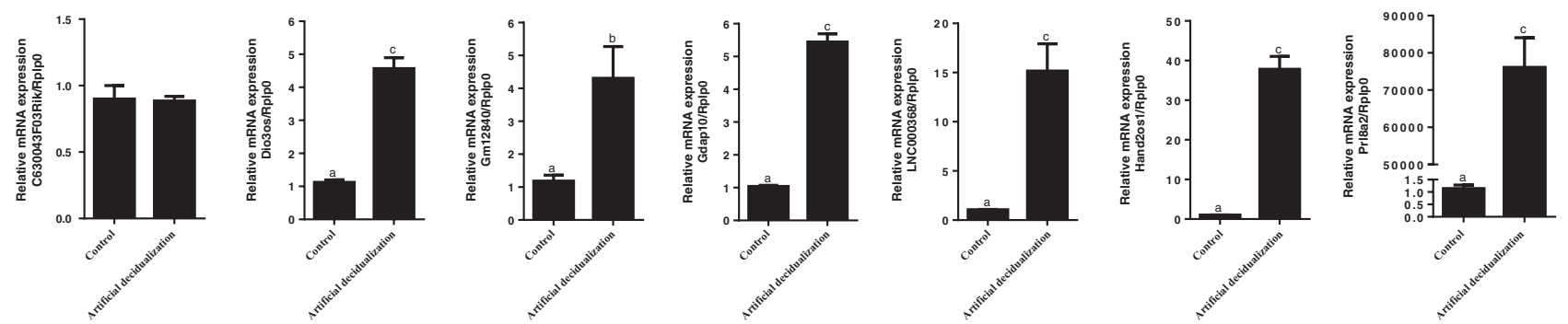

Figure 3 Relative levels of differentially expressed IncRNAs in mice uteri under artificial decidualization were detected by qRT-PCR. Rplp0 was used as a reference gene for normalization. Prl8a2 was detected as a reliable decidualization marker. The data are expressed as the mean \pm S.E.M. of three replicates, and the bar bearing different superscripts indicates a significant difference between the mean values $(P<0.05)$. 
the sub-epithelial stromal cells from days 3 to 5 of pregnancy. A strong Hand2os1 signal was observed in the antimesometrial deciduas, particularly those in the PDZ, which was well formed on day 6 of pregnancy. On days 7-8, Hand2os 1 was highly expressed in almost all areas of the endometrial stroma, including the antimesometrial and mesometrial deciduas. Notably, Hand2os 1 was mainly localized in the nuclei of stromal and decidual cells. No obvious Hand2os 1 signal appeared in the luminal epithelium or glandular epithelium from days 1 to 8 of pregnancy. The gRT-PCR results also confirmed that Hand2os 1 expression was highly elevated on day 4 of pregnancy and reached a peak on days 6 and 7, alongside the process of decidualization (Fig. 1). The spatiotemporal expression pattern of Hand2os 1 during early pregnancy led to the hypothesis that Hand2os 1 may be a critical regulator of stromal cells during decidualization.

\section{Expression of Hand2os1 under artificial decidualization and pseudopregnancy}

Consistent with the results of days 1 to 5 of pregnancy, Hand2os 1 signal was detected in the stromal cells of the non-injected uterine horn, whereas no positive signal was observed in the luminal and glandular epithelium cells (Fig. 5A). Meanwhile, high expression of Hand2os 1 was observed in the decidualized cells following artificial decidualization. The expression levels of Hand2os 1 in the deciduoma were also significantly
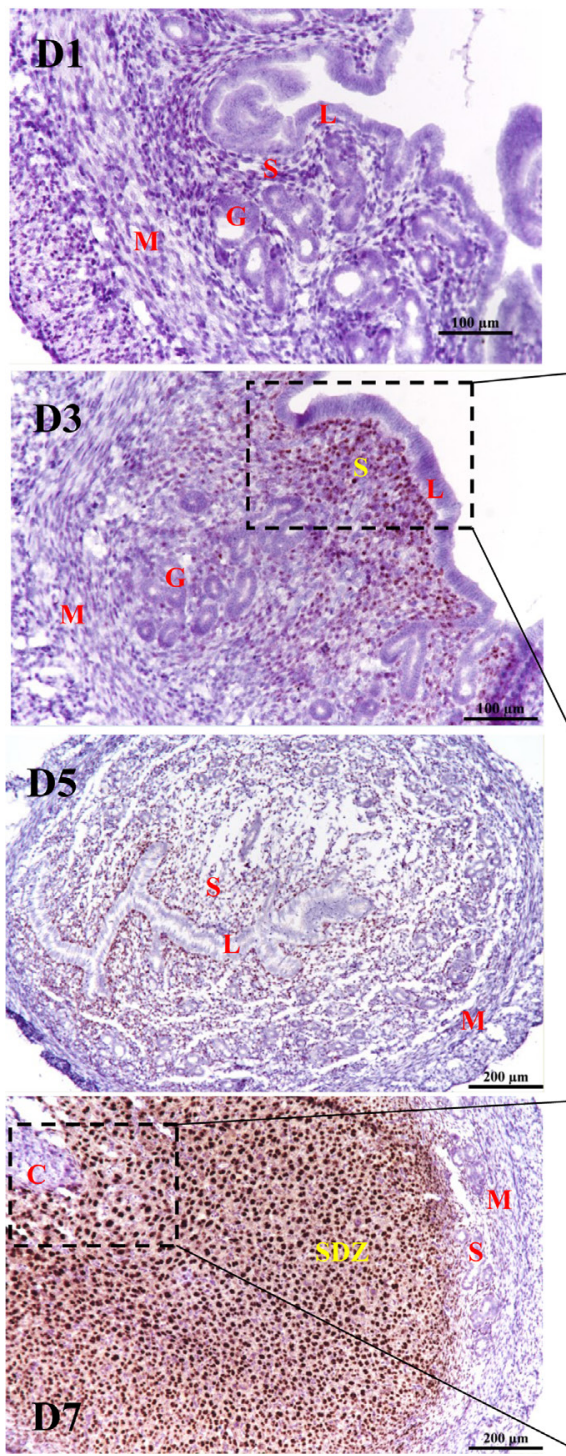
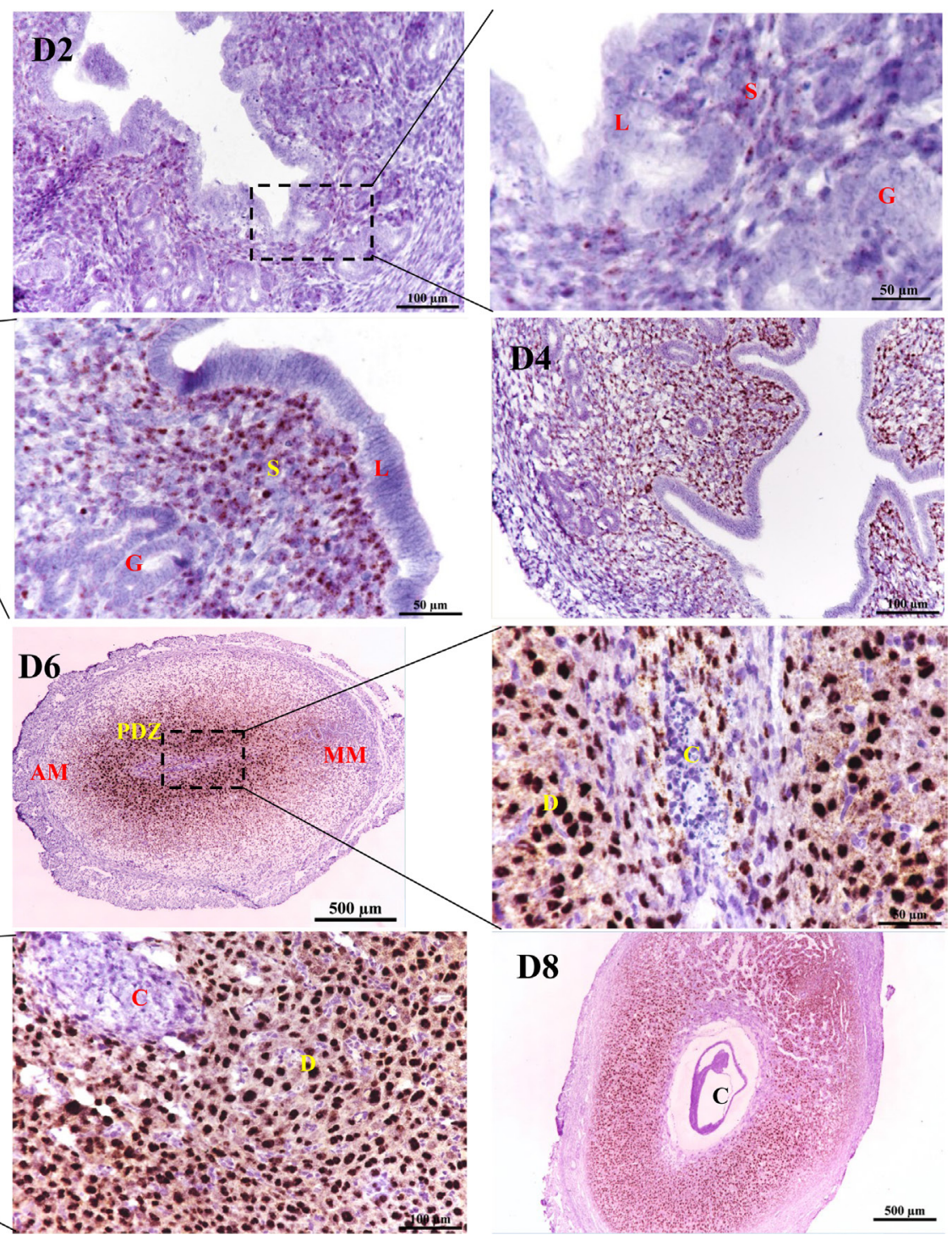

Figure 4 RNAscope of the Hand2os 1 expression pattern in mouse uteri on days 1 to 8 of pregnancy. Day 1 to day 8 (D1-D8) pregnant uterine sections were stained with a Hand2os 1 probe. Positive expression resulted in a brown color. L, luminal epithelium; S, stroma; G, glandular epithelium; M, myometrium; AM, antimesometrial region; MM, mesometrial region; C, conceptus; PDZ, primary decidual zone; SDZ, secondary decidual zone; $\mathrm{D}$, decidual cells. 


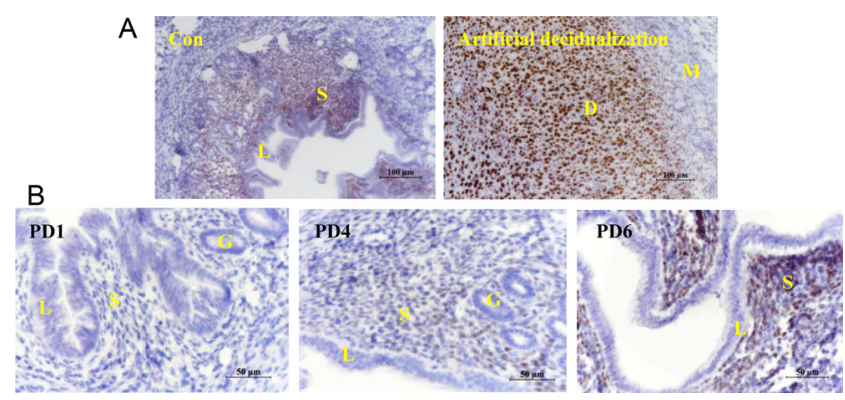

Figure 5 Hand2os 1 expression in mice uteri under artificial decidualization and pseudopregnancy. (A) Hand2os1 expression and localization in the uterine horn under artificial decidualization detected by RNAscope; non-injected uterine horn served as a control. (B) RNAscope analysis of endometrial Hand2os1 expression in a pseudopregnant mouse, day 1 (PD1), PD4, and PD6. G, glandular epithelium; L, luminal epithelium; S, stromal cells; D, decidual cells; $M$, myometrium.

higher than those in the control group, indicating that Hand2os 1 expression in decidua was not dependent on the presence of embryos $(P<0.05$, Fig. 3$)$. In addition, the pseudopregnancy model further confirmed that the expression of Hand2os 1 in these stromal cells was not dependent on the embryo from days 1 to 6 of pseudopregnancy (Fig. 5B).

\section{Regulation of Hand2os1 expression by ovarian steroid hormones}

To address the influence of $\mathrm{E}_{2}$ and $\mathrm{P}_{4}$ on uterine Hand2os 1 expression, we employed an ovariectomized mouse model injected with $\mathrm{E}_{2}, \mathrm{P}_{4}, \mathrm{E}_{2}$ plus $\mathrm{P}_{4}$, or $\mathrm{P}_{4}$ plus RU486. No Hand2os 1 signal was observed in the control or $\mathrm{E}_{2}$ treatment mice (Fig. 6); however, expression of Hand2os 1 in ESCs was significantly stimulated by $\mathrm{P}_{4}$ treatment, whereas RU486 markedly reduced the $\mathrm{P}_{4^{-}}$ dependent activation of Hand2os 1 stromal expression (Figs 6 and 7A, B). Similar to $\mathrm{P}_{4}$ treatment only, Hand2os 1 expression was also significantly observed in ESCs by a combination of $E_{2}$ and $P_{4}$, implying that $E_{2}$ does not have an antagonistic effect on the $\mathrm{P}_{4}$ upregulation of Hand2os 1 expression (Figs 6 and 7A). On the basis of the previously mentioned observations, we subsequently detected the expression of Hand2os 1 at different time courses following $\mathrm{P}_{4}$ treatment. The Hand2os 1 levels in ESCs significantly increased following $\mathrm{P}_{4}$ injection for $24 \mathrm{~h}$, with peak levels at $3 \mathrm{~h}$ (Figs 6 and $7 \mathrm{C}$ ).
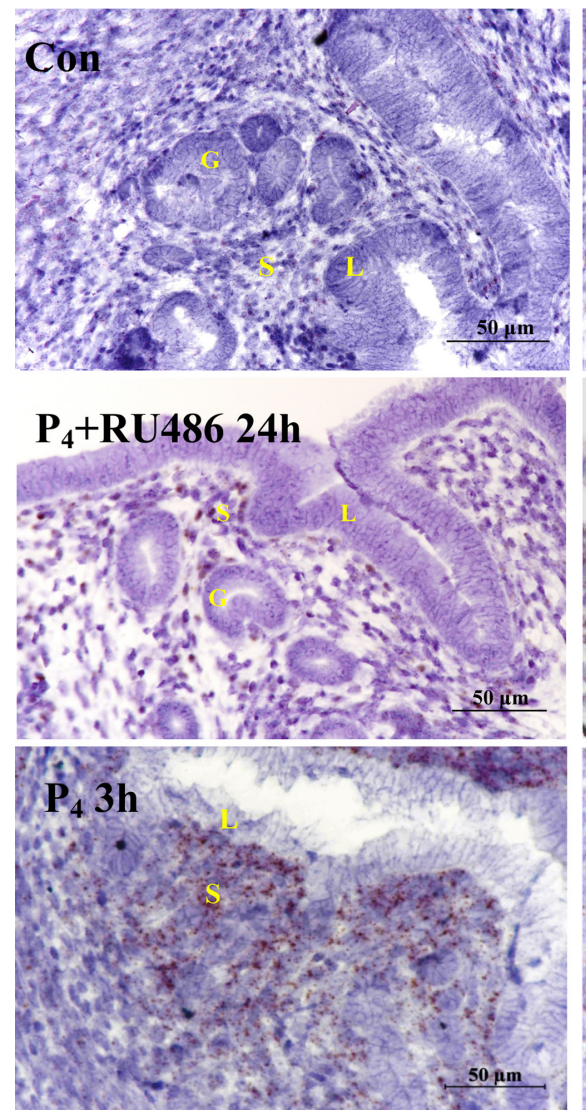
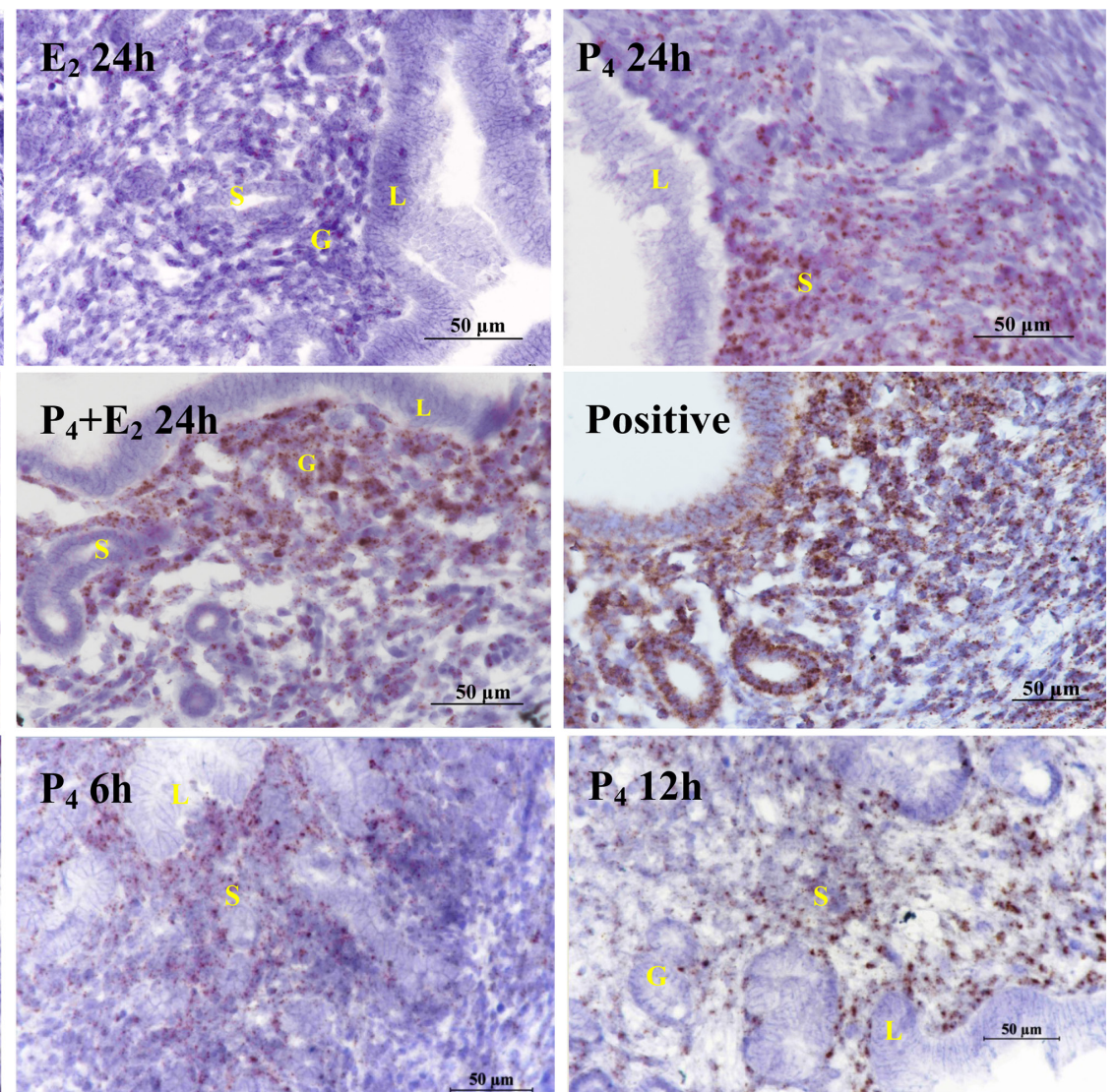

Figure 6 RNAscope of Hand2os 1 expression in the uterus after ovariectomized mice were treated with sesame oil (control), $E_{2}, P_{4}, a$ combination of $\mathrm{E}_{2}$ and $\mathrm{P}_{4}$, or $\mathrm{P}_{4}$ plus RU486. A peptidylprolyl isomerase $\mathrm{B}$ (Ppib) probe was used to replace the Hand2os 1 probe as a positive control. L, luminal epithelium; G, glandular epithelium; S, stromal cells. 

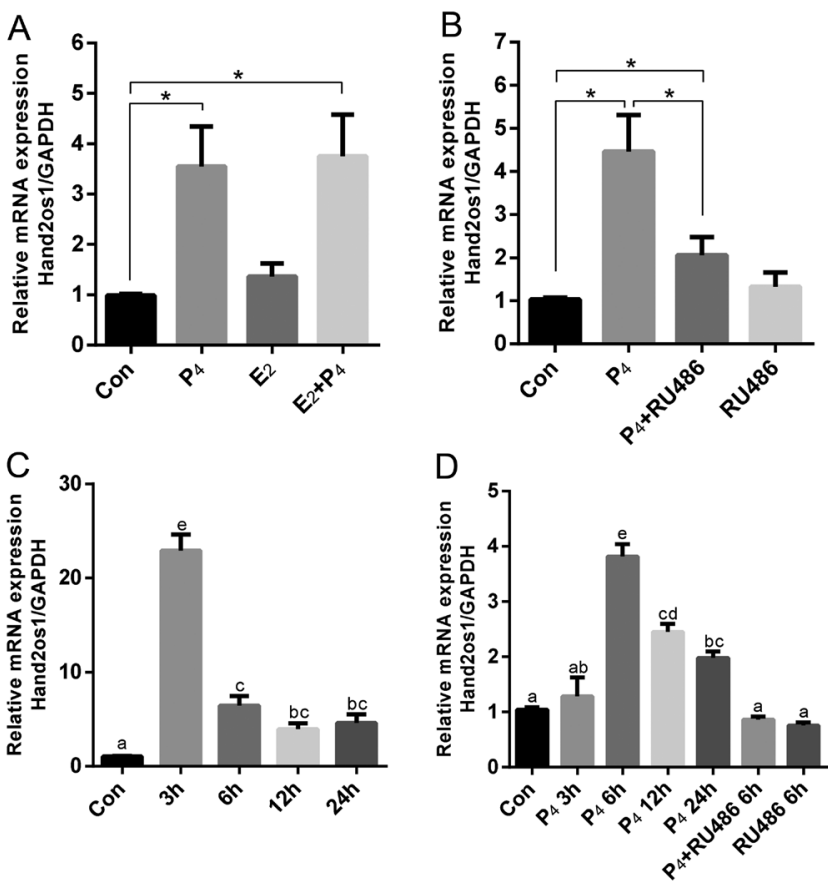

Figure 7 Hormonal regulation of Hand2os 1 expression detected by qRT-PCR. (A) The expression levels of Hand2os 1 in the uterus of ovariectomized mice after treatment with sesame oil (con), $\mathrm{E}_{2}, \mathrm{P}_{4}$, or a combination of $E_{2}$ and $P_{4}$ for 24 h. (B) Hand2os 1 expression in ovariectomized mouse uteri after injection of sesame oil (con), $\mathrm{P}_{4}$, RU486, or $\mathrm{P}_{4}$ plus RU486. (C) Hand2os 1 expression in

ovariectomized mouse uteri after injection of $\mathrm{P}_{4}$ for $3,6,12$, and 24 h. (D) Hand2os 1 expression in the uterine stromal cells treated with $\mathrm{P}_{4}$ for $3,6,12$, and $24 \mathrm{~h}$ or $\mathrm{P}_{4}$ plus RU486 for $6 \mathrm{~h}$. Values represent mean \pm S.E.M. of three independent experiments. Each experiment was repeated at least three times. Student's $t$-test analysis was used to calculate the differences in (A) and (B). ${ }^{*} P<0.05$ was considered statistically significant. One-way analysis of variance was used to calculate the differences in $(C)$ and $(D)$; bars with different letters are significantly different $(P<0.05)$.

To further support the previous mentioned results, we treated ESCs with $\mathrm{P}_{4}$ in vitro and showed that Hand2os 1 expression was distinctly up-regulated during $24 \mathrm{~h}$ of $\mathrm{P}_{4}$ treatment, with peak levels observed at $6 \mathrm{~h}$; in contrast, RU486 markedly reduced the stimulatory effects of $\mathrm{P}_{4}$ on Hand2os 1 expression ( $P<0.05$, Fig. 7D). The results suggest that the induction of Hand2os 1 expression by $\mathrm{P}_{4}$ had been depended on the PR.

\section{Effects of Hand2os1 on decidualization in vitro}

To further verify the role of Hand2os1 in ESC decidualization, we silenced and overexpressed the Hand2os 1 gene in cultured primary ESCs $(P<0.05$; Figs $8 \mathrm{~A}$ and $9 \mathrm{~A})$. The results showed that, although no significant difference was observed in the heart and neural crest derivatives-expressed transcript 2 (Hand2) mRNA levels, silencing of Hand2os 1 expression significantly reduced the differentiation markers for Prl8a2 and Prl3c1 mRNA levels in ESCs during decidualization in vitro $(P<0.05$, Fig. $8 \mathrm{~B}, \mathrm{C}$ and $\mathrm{D})$. Conversely, overexpression of Hand2os 1 was able to increase the mRNA expression of Prl8a2 and $\operatorname{Pr} 3 \mathrm{C} C 1$ genes $(P<0.05$, Fig. 9B and C). Moreover, the expression levels of Hand2 was not affected by Hand2os 1 overexpression (Fig. 9D). These results demonstrate that Hand2os 1 promoted the expression of decidualization-related genes in ESCs and influenced the process of decidualization in vitro.

\section{Discussion}

To date, genome-wide analysis of mouse IncRNAs in pre-implantation embryonic development has been widely reported (Xue et al. 2013, Yan et al. 2013, Liu et al. 2018). LncRNAs are emerging as potentially important regulators in early-stage embryonic developmental processes, including oocyte maturation, zygotic genome activation, and mitochondrial functions (Qiu et al. 2016). Furthermore, IncRNAs may potentially represent attractive biomarkers for developing noninvasive tests for the prediction of oocyte/embryo quality and pregnancy outcome (Bouckenheimer et al. 2016). Successful implantation depends on effecting a synchronized dialog between embryos and the maternal endometrium. Because of less conserved sequencing across phylogenetically related species in terms of nucleotides, the predicted novel IncRNAs cannot currently be inferred by sequence similarity searching (Necsulea et al. 2014). The landscape of IncRNA data sets in endometrial tissue during embryo implantation has, to date, remained nearly completely unexplored. In our previous study, we performed a systematic analysis of IncRNAs in pregnant mouse uteri on days 4 and 5 at implantation and inter-implantation sites using RNA-seq and identified a total of 7764 putative IncRNAs (Wang et al. 2017). During days 6 to 8 of pregnancy, the uterus undergoes a series of dramatic changes in response to an implanting embryo, including stromal proliferation and differentiation into decidual cells, which is a critical process accompanying embryo implantation. Therefore, the purpose of this study was to compile a complete list of IncRNAs expressed during decidualization. We performed deep transcriptome sequencing for mouse endometrium samples collected on days 4, 6, and 8 of pregnancy, respectively. Finally, a total of 2332 putative IncRNA transcripts were identified with high confidence at the whole-genome level, and 510 of these were identified as novel IncRNAs, of which 91\% (464) were classified as lincRNAs.

In recent years, the roles of several IncRNAs in decidualization have been reported. The expression profiling of IncRNAs between the decidua of human preeclamptic and normal pregnancy were identified by RNA-seq (Tong et al. 2018). In human decidualization, LncRNA HK2P1 plays a critical role through accelerating glycolysis via regulation of HK2 expression, effected via competition for miR-6887-3p binding sites 

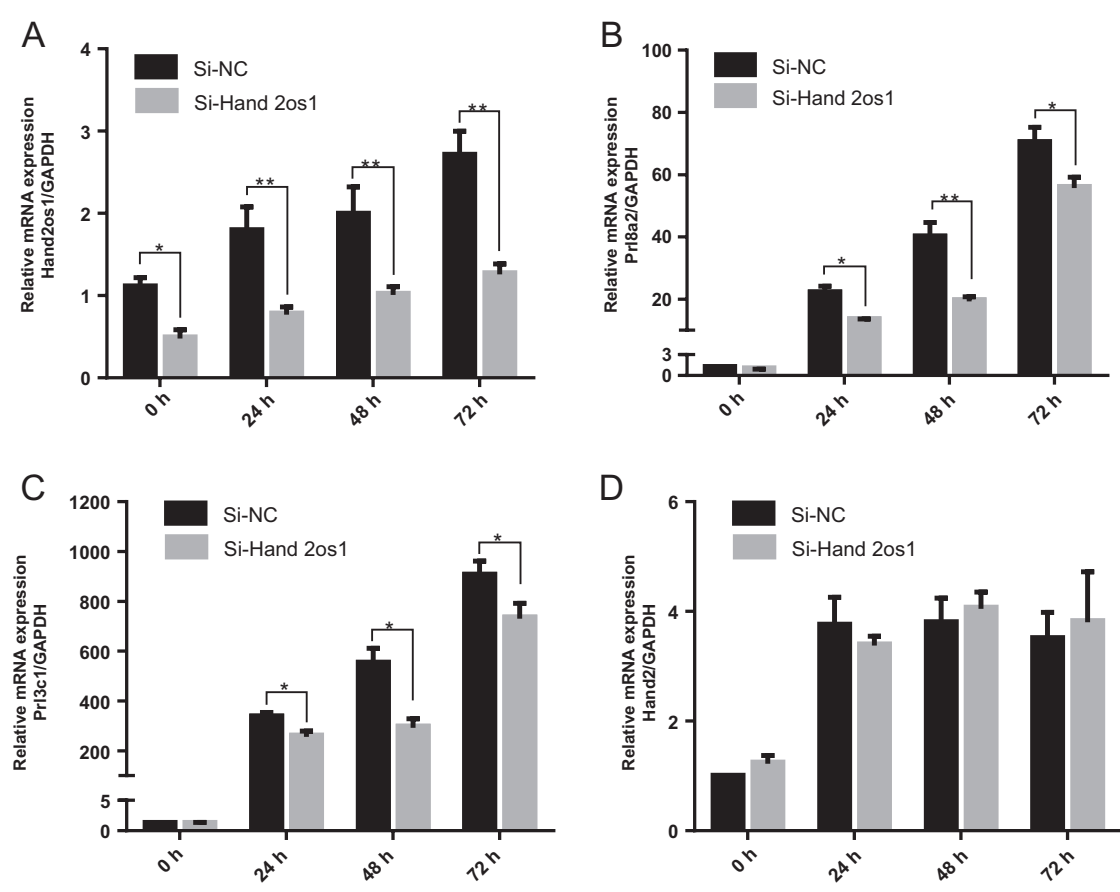

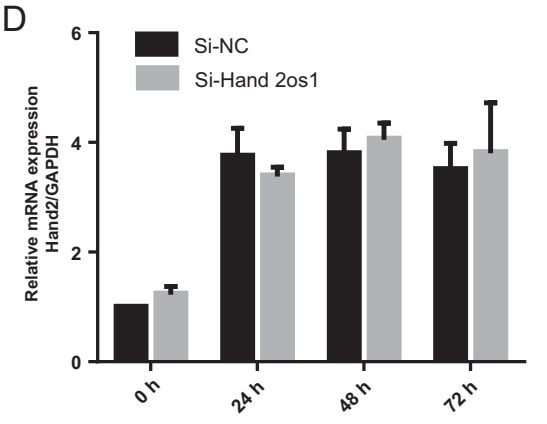

Figure 8 siRNA-mediated knockdown of Hand2os 1 regulated the ESC decidualizationrelated genes' expression during decidualization in vitro. Mouse ESCs collected on day 4 of pregnancy were transfected with scrambled siRNA (si-NC) and Hand2os 1 siRNA (si-Hand2os 1); then decidualization was induced with $\mathrm{P}_{4}(1 \mu \mathrm{M})$ and $\mathrm{E}_{2}(10 \mathrm{nM})$ up to 72 h. qRT-PCR analysis was conducted for Hand2os1 (A), Prl8a2 (B), Prl3c1(C), and Hand2 (D) expression, using RNA collected from the above-noted decidual ESCs at various times. The siRNA treatment reduced Hand2os 1 IncRNA levels by $~ 50 \%$. GAPDH was used as a reference gene for normalization. The data are presented as means \pm S.E.M. for three independent experiments; $* P<0.05,{ }^{* *} P<0.01$ was compared with the si-NC group.
(Lv et al. 2018). The ncRNA LINC00473 expression is highly induced in vitro in human decidualization, via treatment with db-cAMP, and knockdown of LINC00473 attenuates the expression of several crucial decidual transcription factors, as well as WNT4 (Liang et al. 2016). Unfortunately, non-homologous sequencing of IncRNA HK2P1 and LINC00473 in human tissue was found in our RNA-seq results. Dio3os was strongly expressed in the decidual stromal cells and may be important for mouse decidualization via regulation of Dio3 expression (Deng et al. 2014). Consistent with report, Dio3os was shown to be significantly up-regulated in mouse endometrium from pregnancy days 6 to 8 , according to both the RNA-seq and qRT-PCR results in our study. Meanwhile, Dio3os was also highly expressed in artificial and in vitro decidualization. A microarray experiment reported that Gdap10 was highly expressed in acetaminopheninduced liver injury (Kim et al. 2017). Hepatocyte chromosome polyploidization is an important response to liver injury. The polyploidy in decidual cells appear to be crucial for successful embryo implantation and the support of embryo growth during early pregnancy. In our study, Gdap10 was significantly up-regulated alongside the process of decidualization in vivo and in vitro, suggesting that Gdap10 may be involved in differentiation and polyploid formation in mouse ESCs.

With the exception of higher expression in adult mouse heart tissue, northern blot analysis showed Hand2os 1 transcript to also be more strongly expressed in the uterus and placenta tissue (Anderson et al. 2016). In addition, Hand2os 1 was identified in human term placenta by RNA-seq analysis and displayed higher expression levels in female placenta compared with those in male placenta (Anderson et al. 2016). In this study, RNAscope and qRT-PCR further revealed Hand2os 1 to be specifically expressed in the ESCs of mice uteri and was significantly up-regulated during decidualization in normal pregnant and artificial decidualization models. Similarly, elevated expression levels of Hand2os 1 were also observed in decidualizing stromal cells, with a
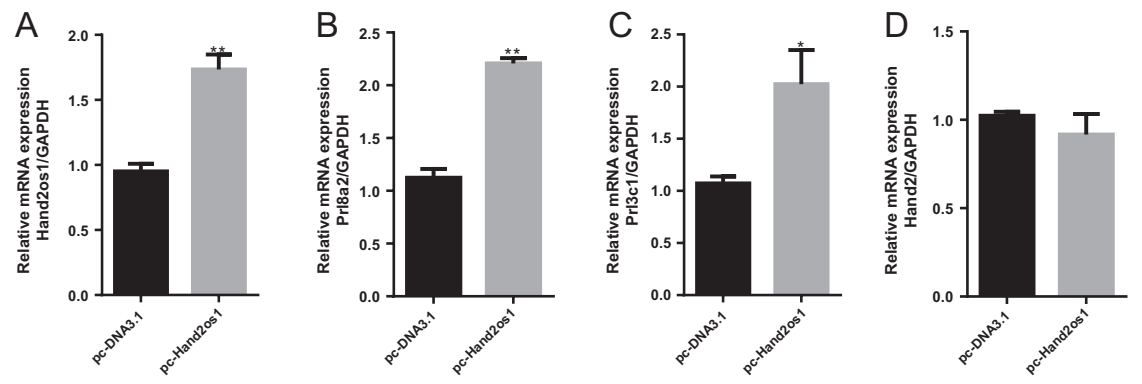

Figure 9 The effects of Hand2os 1 overexpression on the expression of Hand2os 1 (A), Prl8a2 (B), Prl3c1 (C), and Hand2 (D) detected by qRT-PCR. Mouse ESCs collected on day 4 of pregnancy were transfected with the control vector (pc-DNA3.1) and recombinant vector ( $p c-H a n d 2 o s 1)$ and then decidualization was induced with $\mathrm{P}_{4}(1 \mu \mathrm{M})$ and $E_{2}(10 \mathrm{nM})$ for $24 \mathrm{~h}$. The results were normalized to GAPDH. The data are presented as the mean \pm S.E.M. of three independent experiments, and the bar bearing different superscripts indicate significant differences $(P<0.05)$. 
time-dependent increase, after ESCs were induced for in vitro decidualization. Likewise, inhibition of Hand2os 1 with specific siRNA was able to reduce the expression of decidualization markers Prl8a2 and Prl3c1. Conversely, overexpression of Hand2os 1 was able to augment the expression of Pr/8a2 and $\mathrm{Pr} / 3 \mathrm{C} 1$, which further verified the effects of Hand2os1 during decidualization. It is known that Hand2 is essential for embryo implantation and decidualization (Bhurke et al. 2016). Selective knockout of the Hand2 gene in mouse uterine tissue led to implantation failure (Li et al. 2011). A primary study found that Hand2os 1 and Hand2 were co-regulated by a bidirectional promoter with asymmetrical activity (Voth et al. 2009, Anderson et al. 2016). Recently, studies indicated that promoter DNA hypermethylation may be involved in co-down-regulation of Hand2os 1 and Hand 2 in endometrial adenocarcinoma (Yang et al. 2018). However, Hand 2 was not regulated by Hand2os 1 in transcription level (Voth et al. 2009, Yang et al. 2018). The results of Hand2os $1 \mathrm{KO}$ and Hand2os $1^{+/-} \mathrm{Hand}_{2}{ }^{+-}$ mice revealed that the expression of Hand 2 in embryonic heart development depended on the transcription of Hand2os 1 in cis but that the mature Hand2os 1 transcript was not required for this to occur (Anderson et al. 2016). In addition, knockdown or overexpression of mature Hand2os 1 transcripts in HL-1 cells did not alter Hand2 mRNA expression (Anderson et al. 2016). Our results also showed that silencing or overexpression of Hand2os 1 did not change mRNA expression levels of Hand2 in ESCs during decidualization in vitro. However, whether Hand2os 1 also regulates decidualization at the transcriptional level through Hand2 requires further study. Interestingly, similar to the Hand2 gene, increasing expression of Hand2os 1 in the mouse uterus during decidualization was not dependent on the presence of a conceptus (Huyen \& Bany 2011).

In the current study, on days 6 and 8 of pregnancy, when the level of maternal $\mathrm{P}_{4}$ was high, Hand2os 1 was strongly expressed in mice uteri, implying a possible correlation between Hand2os 1 expression and $\mathrm{P}_{4}$ levels during decidualization. In fact, $\mathrm{P}_{4}$ significantly induced Hand2os 1 expression in the ESCs in ovariectomized mice. Additionally, PR antagonist RU486 was able to abrogate the induction of $\mathrm{P}_{4}$ on Hand2os 1 expression during decidualization, both in vivo and in vitro. In addition, our results showed that $E_{2}$ had no significant effect on Hand2os 1 expression and that Hand2os 1 expression was not changed by a combination of $E_{2}$ and $P_{4}$, relative to $P_{4}$ treatment only, indicating that $E_{2}$ appeared to have no antagonistic effect on $P_{4}$ up-regulation of Hand2os 1 expression.

In conclusion, the first comprehensive annotation of IncRNAs in pregnant mouse uteri during decidualization was presented in this paper using deep RNA-seq analysis. Accordingly, this paper provides a valuable resource of functional IncRNAs associated with endometrial decidualization. Additionally, $\mathrm{P}_{4}$-induced Hand2os 1 was specifically expressed in ESCs in a PR-dependent manner and dramatically increased as they underwent decidualization. Although Hand2os 1 is involved in the regulation of mouse decidualization, its precise molecular mechanism still requires additional research.

\section{Supplementary materials}

This is linked to the online version of the paper at https://doi. org/10.1530/REP-19-0401.

\section{Declaration of interest}

The authors declare that there is no conflict of interest that could be perceived as prejudicing the impartiality of the research reported.

\section{Funding}

This research study was funded by the China Postdoctoral Science Foundation (2015M582718), Special Foundation of China Postdoctoral Science (2017T100780), Fundamental Research Funds for the Central Universities (2452019052), and Postdoctoral Science Foundation in Shaanxi Province of China. We also thank Shanshan Li and Zhiwei zhang at Novogene Ltd., Co (Beijing) for their assistance in data processing.

\section{Author contribution statement}

$P L$ and $Y J$ designed the experiments and bioinformatics analysis; $\mathrm{R} C$ and $\mathrm{Y} J$ analyzed the data and drafted the manuscript; $Y \mathrm{~J}, \mathrm{~T} Y$, and $\mathrm{R} \mathrm{Z}$ collected the samples and performed the experiments; $S \mathrm{~L}, \mathrm{X}$ G, and C S prepared figures and performed part of the data analysis. A W reviewed the manuscript. All authors have read and approved the final manuscript.

\section{References}

Anderson KM, Anderson DM, Mcanally JR, Shelton JM, Bassel-Duby R \& Olson EN 2016 Transcription of the non-coding RNA upperhand controls Hand2 expression and heart development. Nature 539 433-436. (https://doi.org/10.1038/nature20128)

Bhurke AS, Bagchi IC \& Bagchi MK 2016 Progesterone-regulated endometrial factors controlling implantation. American Journal of Reproductive Immunology 75 237-245. (https://doi.org/10.1111/aji.12473)

Birney E, Stamatoyannopoulos JA, Dutta A, Guigo R, Gingeras TR, Margulies EH, Weng Z, Snyder M, Dermitzakis ET, Thurman RE et al. 2007 Identification and analysis of functional elements in $1 \%$ of the human genome by the ENCODE pilot project. Nature 447 799-816. (https://doi.org/10.1038/nature05874)

Bouckenheimer J, Assou S, Riquier S, Hou C, Philippe N, Sansac C, Lavabre-Bertrand T, Commes T, Lemaitre JM, Boureux A et al. 2016 Long non-coding RNAs in human early embryonic development and their potential in ART. Human Reproduction Update 23 19-40. (https:// doi.org/10.1093/humupd/dmw035)

Das SK 2009 Cell cycle regulatory control for uterine stromal cell decidualization in implantation. Reproduction 137 889-899. (https:// doi.org/10.1530/REP-08-0539)

Das SK 2010 Regional development of uterine decidualization: molecular signaling by Hoxa-10. Molecular Reproduction and Development 77 387-396. (https://doi.org/10.1002/mrd.21133) 
Deng WB, Liang XH, Liu JL \& Yang ZM 2014 Regulation and function of deiodinases during decidualization in female mice. Endocrinology 155 2704-2717. (https://doi.org/10.1210/en.2014-1015)

Gao Y, Duran S, Lydon JP, Demayo FJ, Burghardt RC, Bayless KJ, Bartholin L \& Li QL 2015 Constitutive activation of transforming growth factor beta Receptor 1 in the mouse uterus impairs uterine morphology and function. Biology of Reproduction 92 34. (https://doi.org/10.1095/ biolreprod.114.125146)

Garrido-Gomez T, Dominguez F, Quinonero A, Diaz-Gimeno P, Kapidzic M, Gormley M, Ona K, Padilla-Iserte P, Mcmaster M, Genbacev $\mathrm{O}$ et al. 2017 Defective decidualization during and after severe preeclampsia reveals a possible maternal contribution to the etiology. PNAS $\mathbf{1 1 4}$ E8468-E8477. (https://doi.org/10.1073/pnas.1706546114)

Hamazaki N, Uesaka M, Nakashima K, Agata K \& Imamura T 2015 Gene activation-associated long noncoding RNAs function in mouse preimplantation development. Development 142 910-920. (https://doi. org/10.1242/dev.116996)

Herington JL, Underwood T, McConaha M \& Bany BM 2009 Paracrine signals from the mouse conceptus are not required for the normal progression of decidualization. Endocrinology 150 4404-4413. (https:// doi.org/10.1210/en.2009-0036)

Huyen DV \& Bany BM 2011 Evidence for a conserved function of heart and neural crest derivatives expressed transcript 2 in mouse and human decidualization. Reproduction 142 353-368. (https://doi.org/10.1530/ REP-11-0060)

Kaitu'u-Lino TJ, Ye L, Salamonsen LA, Girling JE \& Gargett CE 2012 Identification of label-retaining perivascular cells in a mouse model of endometrial decidualization, breakdown, and repair. Biology of Reproduction 86 184. (https://doi.org/10.1095/biolreprod.112.099309)

Kim M, Yun JW, Shin K, Cho Y, Yang M, Nam KT \& Lim KM 2017 Expression levels of GABA-A receptor subunit alpha 3, Gabra3 and lipoprotein lipase, Lpl are associated with the susceptibility to acetaminopheninduced hepatotoxicity. Biomolecules and Therapeutics 25 112-121. (https://doi.org/10.4062/biomolther.2016.076)

Lan X, Jin Y, Yang Y, Lin P, Hu L, Cui C, Li Q, Li X \& Wang A 2013 Expression and localization of Luman RNA and protein during mouse implantation and decidualization. Theriogenology 80 138.e1-144.e2. (https://doi. org/10.1016/j.theriogenology.2013.02.024)

Li Q, Kannan A, DeMayo FJ, Lydon JP, Cooke PS, Yamagishi H, Srivastava D, Bagchi MK \& Bagchi IC 2011 The antiproliferative action of progesterone in uterine epithelium is mediated by Hand2. Science 331 912-916. (https://doi.org/10.1126/science.1197454)

Liang XH, Deng WB, Liu YF, Liang YX, Fan ZM, Gu XW, Liu JL, Sha AG, Diao HL \& Yang ZM 2016 Non-coding RNA LINC00473 mediates decidualization of human endometrial stromal cells in response to cAMP signaling. Scientific Reports 6 22744. (https://doi.org/10.1038/ srep22744)

Liang J, Wang S \& Wang Z 2017 Role of microRNAs in embryo implantation. Reproductive Biology and Endocrinology 15 90. (https:// doi.org/10.1186/s12958-017-0309-7)

Lin P, Jin Y, Lan X, Yang Y, Chen F, Wang N, Li X, Sun Y \& Wang A 2014 GRP78 expression and regulation in the mouse uterus during embryo implantation. Journal of Molecular Histology 45 259-268. (https://doi. org/10.1007/s10735-013-9552-1)

Liu JL \& Wang TS 2015 Systematic analysis of the molecular mechanism underlying decidualization using a text mining approach. PLOS ONE 10 e0134585. (https://doi.org/10.1371/journal.pone.0134585)

Liu KS, Li TP, Ton H, Mao XD \& Chen YJ 2018 Advances of long noncoding RNAs-mediated regulation in reproduction. Chinese Medical Journal 131 226-234. (https://doi.org/10.4103/0366-6999.222337)

Lv H, Tong J, Yang J, Lv S, Li WP, Zhang C \& Chen ZJ 2018 Dysregulated pseudogene HK2P1 may contribute to preeclampsia as a competing endogenous RNA for hexokinase 2 by impairing decidualization. Hypertension 71 648-658. (https://doi.org/10.1161/ HYPERTENSIONAHA.117.10084)

McConaha ME, Eckstrum K, An J, Steinle JJ \& Bany BM 2011 Microarray assessment of the influence of the conceptus on gene expression in the mouse uterus during decidualization. Reproduction 141 511-527. (https://doi.org/10.1530/REP-10-0358)

Mori M, Bogdan A, Balassa T, Csabai T \& Szekeres-Bartho J 2016 The decidua-the maternal bed embracing the embryo-maintains the pregnancy. Seminars in Immunopathology 38 635-649. (https://doi. org/10.1007/s00281-016-0574-0)
Necsulea A, Soumillon M, Warnefors M, Liechti A, Daish T, Zeller U, Baker JC, Grutzner F \& Kaessmann H 2014 The evolution of IncRNA repertoires and expression patterns in tetrapods. Nature 505 635-640. (https://doi.org/10.1038/nature12943)

Paul ABM, Sadek ST \& Mahesan AM 2019 The role of microRNAs in human embryo implantation: a review. Journal of Assisted Reproduction and Genetics 36 179-187. (https://doi.org/10.1007/s10815-018-1326-y)

Pollard JW, Jahan M \& Butterworth PJ 1990 Characterization and expression of uterine and placental alkaline phosphatases in the mouse. Journal of Reproduction and Fertility 89 735-742. (https://doi. org/10.1530/jrf.0.0890735)

Ponting CP, Oliver PL \& Reik W 2009 Evolution and functions of long noncoding RNAs. Cell 136 629-641. (https://doi.org/10.1016/j. cell.2009.02.006)

Qiu JJ, Ren ZR. \& Yan JB 2016 Identification and functional analysis of long non-coding RNAs in human and mouse early embryos based on single-cell transcriptome data. Oncotarget 7 61215-61228. (https://doi. org/10.18632/oncotarget.11304)

Schatz F, Guzeloglu-Kayisli O, Arlier S, Kayisli UA \& Lockwood CJ 2016 The role of decidual cells in uterine hemostasis, menstruation, inflammation, adverse pregnancy outcomes and abnormal uterine bleeding. Human Reproduction Update 22 497-515. (https://doi.org/10.1093/humupd/ dmw004)

Shea K \& Geijsen N 2007 Dissection of 6.5 dpc mouse embryos. Journal of Visualized Experiments : JoVE 160. (https://doi.org/10.3791/160)

Sroga JM, Ma X \& Das SK 2012 Developmental regulation of decidual cell polyploidy at the site of implantation. Frontiers in Bioscience 4 1475-1486. (https://doi.org/10.2741/s347)

Taylor DH, Chu ET, Spektor R \& Soloway PD 2015 Long non-coding RNA regulation of reproduction and development. Molecular Reproduction and Development 82 932-956. (https://doi.org/10.1002/mrd.22581)

Tong J, Zhao W, Lv H, Li WP, Chen ZJ \& Zhang C 2018 Transcriptomic profiling in human decidua of severe preeclampsia detected by RNA sequencing. Journal of Cellular Biochemistry 119 607-615. (https://doi. org/10.1002/jcb.26221)

Voth H, Oberthuer A, Simon T, Kahlert Y, Berthold F \& Fischer M 2009 Coregulated expression of HAND2 and DEIN by a bidirectional promoter with asymmetrical activity in neuroblastoma. BMC Molecular Biology 10 28. (https://doi.org/10.1186/1471-2199-10-28)

Wang Q, Wang N, Cai R, Zhao F, Xiong Y, Li X, Wang A, Lin P \& Jin Y 2017 Genome-wide analysis and functional prediction of long non-coding RNAs in mouse uterus during the implantation window. Oncotarget 8 84360-84372. (https://doi.org/10.18632/oncotarget.21031)

Wu GM, Gentile L, Fuchikami T, Sutter J, Psathaki K, Esteves TC, ArauzoBravo MJ, Ortmeier C, Verberk G, Abe K et al. 2010 Initiation of trophectoderm lineage specification in mouse embryos is independent of Cdx2. Development 137 4159-4169. (https://doi.org/10.1242/ dev.056630)

Xiong Y, Li W, Lin P, Wang L, Wang N, Chen F, Li X, Wang A \& Jin Y 2016 Expression and regulation of ATF6alpha in the mouse uterus during embryo implantation. Reproductive Biology and Endocrinology 1465. (https://doi.org/10.1186/s12958-016-0199-0)

Xue ZG, Huang K, Cai CC, Cai LB, Jiang CY, Feng Y, Liu ZS, Zeng Q, Cheng LM, Sun YE et al. 2013 Genetic programs in human and mouse early embryos revealed by single-cell RNA sequencing. Nature $\mathbf{5 0 0}$ 593-597. (https://doi.org/10.1038/nature12364)

Yan LY, Yang MY, Guo HS, Yang L, Wu J, Li R, Liu P, Lian Y, Zheng XY, Yan J et al. 2013 Single-cell RNA-Seq profiling of human preimplantation embryos and embryonic stem cells. Nature Structural and Molecular Biology 20 1131-1139. (https://doi.org/10.1038/nsmb.2660)

Yang X, Wang CC, Lee WYW, Trovik J, Chung TKH \& Kwong J 2018 Long non-coding RNA HAND2-AS1 inhibits invasion and metastasis in endometrioid endometrial carcinoma through inactivating neuromedin U. Cancer Letters 413 23-34. (https://doi.org/10.1016/j. canlet.2017.10.028)

Received 28 August 2019

First decision 18 October 2019

Revised manuscript received 1 December 2019

Accepted 6 January 2020 